\title{
Personalized Enhancement Smoking Cessation Training Program (PEP)
}

\author{
V. Joyce Lim, Naomi N. Modeste ${ }^{1}$, and Yolanda Williams \\ ${ }^{1}$ Loma Linda University
}

\begin{abstract}
Smoking is the number one preventable public health problem in America. The African America community has a disproportionately high rate of smoking related diseases and illnesses compared to some other population groups. The purpose of this project was to train Faith-based members to conduct smoking cessation programs among underserved African Americans and to educate youth and adults about the harmful effects of second hand smoke. Twenty-one individuals were recruited into the program and 17 completed the training. As a result of the training, 118 persons attended cessation programs conducted by the teams.
\end{abstract}

(C) 2003 Californian Journal of Health Promotion. All rights reserved.

Keywords: Faith-based, training, smoking cessation, African Americans

\section{Introduction}

Cigarette smoking is the number one preventable public health problem in America. African Americans are disproportionately affected by diseases and illnesses related to smoking (Okuyemi, Richter, Ahluwalia, Mosier, Nazir, Resnicow, 2002). In addition there is little information regarding strategies for reducing smoking in this population. In the CDC Bulletin (1993), it was noted that smoking cessation programs were developed for Asian/ Pacific Islanders, American Indians/ Alaskan Natives, and Hispanics, but not for African Americans.

The overall smoking prevalence for San Bernardino County in the African American population is 24.1\% (California Health Interview Survey, UCLA, 2001). MoonHoward (2003) reports that African Americans, particularly women, may start smoking later in life beyond their adolescent age. However, youth from low socioeconomic homes may actually start smoking earlier (Beech \& Scarinci, 2003). This may be one of the reasons for a greater percent of women smoking within the 25- 44 age group. It is also felt that African Americans smoke fewer cigarettes when compared to Caucasians, but they share a far greater burden of smoking related health problems. It is therefore important to plan programs that aim at reducing smoking among African Americans (Okuyemi et. al., 2002). Research among African American smokers examining depressive symptoms and smoking cessation, found that depressive symptoms were associated with level of smoking, but not with inability to quit smoking. Most of these smokers were also using the nicotine patch (Catley, Ahluawlia, Resnicow, \& Nazir, 2003).

Although there has been growth in research and knowledge about smoking cessation among groups, there is a gap in the literature when dealing with the issue of smoking cessation interventions among African Americans. There is research indicating that smokers with lower educational levels and socioeconomic status may find it more difficult to quit smoking and to stay quit. There is indication that people with lower socioeconomic backgrounds and education levels may also return to smoking more readily than people in higher socioeconomic and educational levels (Droomers, Schrijvers, Machenback, 2002; Manfredi, Lacey, Warnecke, \& Buis, 1992; McBride, Pollack, Lyna, Lipkus, Sama, Bepler, 2001). Many African Americans fall into these categories, and particularly from within the priority population on which we were focusing. We can, however, work at reducing 
harm caused by exposure to cigarette toxins in this population.

The purpose of this program was to train individuals from churches, hereafter referred to as "faith-based" organizations, to conduct stop smoking programs and tobacco education/awareness including the effects of second hand smoke among African Americans, in communities served by the "Faith-based" organizations and the zip codes targeted by Westside Brighter Vision for intervention. Faithbased organizations were selected because they are important to the African American population and provide easy access to programs for the families and the community they represent. Initiating health programs within their churches may be more meaningful and personal. A broader segment of the African American population can be reached through faith-based initiatives.

\section{Background}

A one-year grant from the San Bernardino County government to the Westside Brighter Vision Foundation made this training available. The geographic area covered all five supervisory districts in San Bernardino County. A church in one city from each district was chosen. The cities included Victorville, Rancho Cucamonga, Fontana, Highland, San Bernardino and Rialto. The priority population was African Americans in these neighborhoods with special emphasis directed to youth, adults, and women within the childbearing age group. The overall smoking prevalence in the African Americans is $24.1 \%$, higher than the $20.3 \%$ rate for other racial/ethnic groups in San Bernardino County. Many women within their childbearing years have connections with churches or Faith-based sites. Meeting with the youth early in their smoking experience may increase the chance of successful cessation. Faith-based sites can also target young women and their families to decrease the effects of second hand smoke in the homes.

\section{Program Goals}

The program consisted of three main goals: 1) to train members of the Faith community in San Bernardino County to conduct smoking cessation programs for African Americans; 2) to conduct smoking cessation programs for African Americans at neighborhood sites in San Bernardino County; and 3) to reduce the number of African American youth and adults smoking cigarettes in San Bernardino County.

\section{Program Objectives}

Specific measurable objectives for this project were:

1. By December 31, 2001, 21 members of the Faith community will be trained to conduct smoking cessation programs at seven faithbased sites.

2. By August 15, 2002, each team will have conducted four smoking cessation programs for 280 smokers.

3. By September 30, 2002, 280 African American Smokers within the youth and adult populations will have attended at least one smoking cessation program, and of that number, 25\% will have stopped smoking for a period of three months.

\section{Training Program}

Prior to beginning the training program, a curriculum was developed and used as a teaching tool for the teams. Each team was given the opportunity to recommend modifications that were deemed applicable for clients at their sites, and to be involved in the final form of the curriculum development and delivery, giving them some ownership of the program. The African American population often represents diversity within racial similarity because of differences in socio-economics, education, and national origin; therefore differences in congregations at each site were expected.

The program consisted of two weeks of in-depth training, 5 hours per day, 4 days per week, at one training site, to be followed by 7 weeks of 5 hours meeting once per week. Topics covered during the two-week intensive training included information pertinent to smoking and health, effects of second hand smoke, normal physiology of the heart and lungs, physiological effects of smoking, effects of smoking on the family and surroundings, how people change, experiential learning, the transtheoretical model 
(Prochaska \& DiClemente, 1992), nicotine replacement therapy, class organization, record keeping, church mobilization, marketing and advertising, and a number of other topics. A specialist conducted lung volume capacity tests for pulmonary function showing them first hand how this test is done and what the results can be. A training manual was prepared by the program coordinator and provided for each trainee.

\section{Theoretical Framework}

The transtheoretical model (TTM) uses stages of change to integrate processes and principles of change from across major psychological theories of change, hence the name transtheoretical. The principal investigators in this model were J.O. Prochaska, and C. DiClemente (Prochaska, Redding, \& Evers, 1997). The thrust was to find out what processes people use to make personal life changes and look at them in the context of or explain them by some psychological theory in practice. Their comparative analysis identified only 10 processes of change among these theories. Their initial studies were in smoking (Stern, Prochaska, Velicer, \& Elder, 1987), but they expanded the model to include a broad range of health and mental behaviors.

The ten processes of change are: consciousness raising, dramatic relief, self-reevaluation, environmental reevaluation, self liberation, helping relationships, counter-conditioning, contingency management, stimulus control, and social liberation. This model proposes a construct of five stages of change: precontemplation, contemplation, preparation, action, and maintenance. In the early stages, people apply cognitive, affective and evaluative processes to progress through the stages. In later stages, people rely more on commitments, conditioning, contingencies, environmental controls, and support for progressing toward termination.

Participants were trained to apply these five stages of change in working with individuals who wanted to quit smoking, as they progressed from pre-contemplation to contemplation, to preparation and to the action stage where they actually were helped to quit smoking as they joined the program. Finally, the maintenance phase was applied through telephone follow up and encouragement.

The TTM was chosen for use in this program because in most populations, less than $20 \%$ of smokers are in the preparation stage, approximately $40 \%$ are in the contemplation stage, and another $40 \%$ in the pre-contemplation stage (Velicer, Favor, Prochaska, Abrams, Emmons, \& Pierce 1995). Thus, action-oriented cessation programs will not match the needs of the majority of smokers including African Americans.

\section{Program Evaluation}

Process evaluation was carried out throughout the life of the program, and involved a pretestposttest, teacher evaluation, course evaluation, participant evaluation and evaluation of practice sessions. The instrument for the pretest was developed and given on the first day of the program and included questions on attitudes toward smoking, beliefs about smoking and health, and knowledge about smoking and health. The posttest was administered at the end of the seven-week training. Evaluation tools were developed and implemented, data was gathered, entered, analyzed and disseminated through written quarterly reports to the funding agency and other parties involved.

Participants were asked to evaluate the presentations and to indicate what part(s) of the course benefited them most and to share comments that may help improve the course. In evaluating the presentations they given several statements related to the presentations and were to rank them on a scale of $0-5,0=$ Poor and $5=$ Excellent. Results are shown in Table 1. 
Table 1

Ranking Of Items For Evaluation Given In Percentage

\begin{tabular}{|l|r|r|r|}
\hline \multicolumn{1}{|c|}{ Statements } & \multicolumn{1}{c|}{ Good } & \multicolumn{1}{c|}{ Very Good } & Excellent \\
\hline Apparent preparation of presenters & 11.8 & 17.6 & 70.6 \\
\hline Control of discussion and feedback & 6.3 & 37.5 & 56.3 \\
\hline Involvement of trainees in discussion / activities & & 35.3 & 64.7 \\
\hline Apparent relevance of information & 17.6 & 5.9 & 76.5 \\
\hline Ability to hold audience level of interest & 5.9 & 17.6 & 76.5 \\
\hline
\end{tabular}

All trainees (100\%) said that the speakers were easy to follow. The majority (88\%) said they had enough time for questions. Participants were asked if they thought that they were ready to conduct smoking cessation programs on their own, given the information they received from the training program; $76 \%$ felt that they were ready to conduct programs, $6 \%$ said they were not ready and $18 \%$ were not sure.

Participants who attended smoking cessation programs were provided with a form to evaluate all the classes. Of those completing the evaluation, 22 (100\%) indicated that they enjoyed the program. Sixty eight percent rated the program as excellent and $32 \%$ rated it as good, there were four categories, but no one checked average or poor. Participants were asked if the program activities helped them to adopt any new health or lifestyle changes and were give three items for selection. Twenty five percent said they were thinking about it and 75\% said Yes, Definitely. There was no opportunity to say what those changes were. They were also asked how they would rate the instructor(s); 46\% said Good and 54\% rated them Excellent. There were two more categories - Average and Poor, but no one checked those ratings. As to whether the information was useful to them, $86 \%$ said that almost all of the information was useful and $14 \%$ said that most of it was useful. There were no smokers among the trainees, only ex-smokers. Participants were asked if the program would have motivated them to stop smoking, 79\% said Yes and 21\% said No.

A final evaluation of the training program consisting of 12 questions was conducted in December 2002. In order to receive honest answers, the evaluation was mailed to each trainee with a self-addressed stamped envelope for returning the completed questionnaire. They were instructed not to write their names on the paper. Unfortunately, only seven of the trainees (less than 50\%) returned the form. The results are from these seven, and may not be representative of all the trainees.

The trainees were asked if they felt sufficiently trained to conduct smoking cessation programs on their own all seven $100 \%$ said yes. Trainees were also asked about the length of the program and were to indicate whether the program was “Too Long”, “Too Short”, or “Just Right”. Of those responding, 67\% said that it was Too Long, $17 \%$ said it was Too Short and $16 \%$ said that it was Just Right. As to whether their knowledge of smoking increased after the training, all of those responding said yes.

There was some concern that the time between the training and the actual smoking intervention was too short. However, this question was asked in the evaluation and of the six who answered that question, four (67\%) felt that there was just enough time between the training and the intervention and two (33\%) felt that the time was too short. Again, this is not representative of the group that was trained. If all 17 persons participated in the evaluation, the responses may be quite different. Each person who did the evaluation felt that their visit to observe a current smoking cessation program provided a motivation to conduct their own, was very helpful or was somewhat rewarding.

The trainees were also asked what part of the training program benefited them the most and these were their responses: "dealing with people", "stages of change for smokers", "equal benefit from all of the training", "the needs lecture", "health education and outreach" and 
“needs of African Americans”. They were also to state what part of the training did they benefit from the least and the responses were: "the marketing portion was no good”, "administration", and "small group role playing". Three of them did not respond to this question.

The trainees were asked to share their opinion about the training manual. Responses were: "no comments", "very complete", "the manual was not complete", " the manual needs more tools to refer to", "good", "the training manual had too much information", "contained some essential items, but a great deal of it was unnecessary", "was very well put together, all of it is good".

\section{Results \& Accomplishments}

Seven teams of three individuals were recruited from seven churches within the supervisory districts. Twenty-one individuals registered initially for the program. An in-depth training was conducted within the first three months of the intervention and 17 individuals from the Faith Community, who remained with the program, were trained to conduct stop smoking programs.

\section{Demographics of Trainees}

Of those trained, 6 were males and 11 females. The average age was 49 years. Their yearly income ranged from $\$ 10,000$ or less (2), $\$ 25,000-\$ 35,000 \quad(4), \quad 35,100-\$ 45,000 \quad(3)$, $\$ 45,100-\$ 60,000$ (7), and $\$ 70,000$ or more (1). Ten trainees were married, three single, two divorced, and two widowed. The educational levels were: One trainee had a GED, 10 had one or three years of college, two had an Associate of Arts (AA) degree, two had a bachelors degree, one completed a masters degree, and one had a doctorate. Eight trainees said they never smoked, one smoked for one month only and stopped, one smoked for five years, two smoked for eight years, one for 10 years, one for 12 years, one for 20 years, one for 32 years, and one smoked close to 40 years. However, they were all non-smokers at time of training.

\section{Pre/Post Test Results}

Results from the pretest show that all of the respondents believed: 1) smoking increases the risk of lung cancer and heart disease; 2) secondhand smoke is harmful to the health of non-smokers; 3) strongly disagreed that one can smoke in the car with children so long as the windows are opened; 4) smoking at home is acceptable if the children are not in the same room.

Participants were to indicate their level of agreement with a number of other statements: $90 \%$ strongly disagreed that it is alright for women to smoke if they are overweight, strongly disagreed that it does not matter if a person smokes because you have to die from something; $90 \%$ strongly disagreed that it is okay for a woman to stop smoking during her pregnancy and start again after the baby is born, and also strongly disagreed that it is better for a man to smoke if he is overweight than a woman. Eighty-nine percent strongly disagreed that cigarette smoking is not as harmful as the reports show and 95\% strongly disagreed that it is okay to smoke if you are not smoking around people.

One of the goals of the program was for the trainees to conduct smoking cessation programs for African Americans at neighborhood sites in San Bernardino County. The objective was for each team to conduct four smoking cessation programs for a total of 280 smokers, each team being responsible for recruiting 40 smokers. While most of the teams conducted smoking cessation programs, this goal or objective was partially met. The figures accounted for at the end of December 2002 were as follows: 197 persons were oriented into smoking cessation programs and received some type of information about smoking and health, 118 actually attended classes, and 35 persons quit smoking. Participants were allowed to register for the smoking cessation program and this provided necessary information for follow-up, as well as information relating to their smoking habits and their readiness to quit. Those who quit were followed up by phone calls and it was reported that most of them were maintaining. The characteristics of smokers who attended and quit are presented in Table 2. 
Table 2

Characteristics of Smokers ( $\mathrm{N}=35)$

\begin{tabular}{|l|r|r|}
\hline \multicolumn{1}{|c|}{ Variable } & Number & \multicolumn{1}{|c|}{ Percent } \\
\hline Gender & & \\
\hline Male & 7 & 20 \\
\hline Female & 28 & 80 \\
\hline Age & & \\
\hline 18-25 years old & 4 & 13 \\
\hline 26-35 years old & 3 & 9 \\
\hline 36-45 years old & 7 & 23 \\
\hline 46-55 years old & 10 & 32 \\
\hline 56-65 years old & 7 & 23 \\
\hline$\geq 66$ years old & 0 & 0 \\
\hline Age Began Smoking & 1 & 5.3 \\
\hline$<10$ years old & 6 & 31.6 \\
\hline 10-15 years old & 6 & 31.6 \\
\hline 16-19 years old & 6 & 31.6 \\
\hline$>20$ years old & & \\
\hline Type of Cigarette & 19 & 86 \\
\hline Filtered & 3 & 14 \\
\hline Unfiltered & & \\
\hline
\end{tabular}

\section{Discussion}

The number one goal of this project was to train members of the Faith Community in San Bernardino County to conduct smoking cessation programs for African Americans - a group disproportionately affected by the ill effects of tobacco use. Faith-based sites were selected because the church plays a vital role in African American culture; occupying as influential a position as most any other institution. For many African American families, the church is the hub of social and educational activities. It makes sense to extend this influence into an area of health where there is a great need for intervention. Pastors were instrumental in choosing the trainees for each church. The people selected were church leaders and this may have impacted their success in recruiting smokers from among their members. Apparently smoking is an in the closet behavior that members were reluctant to reveal to their leaders.

Prior to beginning the program, a training manual was developed for each participant. The manual was titled "Ready to Quit Smoking
Cessation Program" and was in the form of a three-ring binder. The binder included a "Trainee contract form," "Level of Commitment Exercise Form", "information on how the stipend was going to be disbursed, "Job Description”, "Criteria for Trainers”, the weekly program, and several other pieces of information necessary for conducting smoking cessation programs.

On the first day of the training each participant (trainee) received a manual with a limited number of printed information. However, each day they were given material on the theoretical model that was used and on smoking and health to add to the manual and by the end of the program period each trainee had a completed manual. The purpose of the manual was to provide the trainees with a tool to assist them in conducting cessation programs.

The training program was video taped. Therefore, trainees who missed a session could have viewed the video tape and receive the information that was discussed. In this way each one would have received the full training. 
On the opening day, participants were asked to complete the trainee contract form committing them to the hours and days designated for training. They were also given a short form with sentence beginnings to be completed at the end of the session.

Each group had the opportunity to role play how they would welcome smokers into a cessation class, what the classes would entail, demonstrate how to register people, assess them and assign them into groups according to their readiness to quit, and to make a presentation. Each group did something different but the main focus remained the same.

Although the pre and post test responses did not indicate dramatic change, there is evidence that the training program provided useful information that the trainees can use; information that changed their thinking regarding smoking and health and their attitudes and beliefs about smoking and health. Our observation is that there has been a growth process over the months of training.

The objective of having 280 African American Smokers attend at least one smoking cessation program by December 2002 was partially met. Only 118 (less than 50\%) attended classes. It should be noted that there was a short period of time to really get smokers into sessions and unless they were ready to quit at time of intervention, the success rates would not be very high. More time should have been allotted to recruiting smokers into programs to achieve this objective.

It is encouraging, however, that the majority of trainees have conducted smoking cessation programs for smokers in different stages of change. Programs were mainly conducted at church sites. However, some were also conducted at other community sites and in homes. The program has ended and the trainees are left with tools to assist them with future programs.

The final goal was to assist in the establishment of a library in each church that was involved in the program. While some effort was made to establish a library, most of what was done could be considered displays. However, the library concept may not have been fully understood. There were no records of use and it is unclear how the system was organized and promoted. The trainees needed much more help and information in setting up a library, selecting materials that could be placed in the library, and how the library can be accessed and used by the church as well as the communities being served.

\section{Acknowledgements}

The authors wish to acknowledge Westside Brighter Vision Foundation who received funding for this program and provided the facilities from which we operated; The Health and Human Services System of San Bernardino County who provided the funding. In addition we acknowledge the help of Marlon Daniel, a student who worked with the program, Duane Watson for video taping training cessions, and the department of respiratory therapy from Loma Linda University School of Allied Health Professions for the spirometry testing provided each trainee.

\section{References}

Beech, B. M., \& Scarinci, I.C. (2003). Smoking attitudes and practices among low-income African Americans: qualitative assessment of contributing factors. American Journal of Health Promotion, 17, 231-39.

Catley, D., Ahluwalia, J. S., Resnicow, K., and Nazir, N. (2003). Depressive symptoms and smoking cessation among inner-city African Americans using the nicotine patch. Nicotine and Tobacco Research, 5(1): 61-68.

Centers for Disease Control and Prevention. (1993). Smoking cessation during previous year among adults, USA, 1990,1991. MMWR Weekly, 42(26), 504-507.

Droomers, M., Schrijvers, C. T., Mackenbach, J. P. (2002). Why do lower educated people continue smoking? Explanations from the longitudinal GLOBE study. Health Psychology, 21, 263-272. 
Manfredi, C., Lacey, L., Warnecke, R., and Buis, M. (1992). Smoking-related behavior, beliefs, and social environment of young black women in subsidized public housing in Chicago. American Journal of Public Health, 82, 267-272.

McBride, C. M., Pollak, K. I., Lyna, P., Lipkus, I. M., Samsa, G. P., and Bepler, G. (2001). Reasons for quitting smoking among low-income African American smokers. Health Psychology, 20, 334340.

Moon-Howard, J. (2003). African American women and smoking: starting later. American Journal of Public Health, 93, 418-20.

Okuyemi, K. S., Richter, K. P., Ahluwalia, J. S., Mosier, M. C., Nazir, N., Resnicow, K. (2002). Smoking reduction practices among African American smokers. Nicotine and Tobacco Research, 4, S16773.

Prochaska, J. O., \& DiClemente, C. C. (1992). Stages of change in the modification of problem behaviors. In M. Herson, R. M. Eisler, \& P. M. Miller (Eds). Progress in behavior modification. (pp. 154-206). Homewood, ILL: Sycamore.

Prochaska, J. O., Redding, C. A., and Evers, K. (1997). The transtheoretical model. In K. Glantz, F. M. Lewis, \& B. K. Rimer (Eds.). Health behavior and health education theory, research, and practice, 2nd edition (pp60-84). San Francisco, CA: Jossey-Bass, Inc.

Stern, R. A., Prochaska, J. O., Velicer, W. F., \& Elder, J. P. (1987). Stages of adolescent cigarette smoking acquisition: Measurement and sample profiles. Addictive Behaviors, 12, 319-329.

Velicer, W. F., Favor, J. L., Prochaska, J. O., Abrams, D. B., Emmons, K. M., \& Pierce, J. P. (1995). Distribution of smokers by stage in three representative samples. Preventive Medicine, 24, 401411.

2001 California health interview survey (CHIS 2001). California Department of Health Services: UCLA Center for Health Policy Research, Los Angeles, CA.

\author{
Author Information \\ V. Joyce Lim, DrPH \\ Project Coordinator \\ Retired Professor \\ P. O. Box 484 \\ Loma Linda, CA 92354 \\ Naomi N. Modeste, DrPH* \\ Professor, Loma Linda University \\ School of Public Health \\ Loma Linda, CA 92350 \\ Phone: 909-558-4575 \\ E-Mail: nmodeste@sph.llu.edu \\ Yolanda Williams, MPH \\ Private Consultant \\ 13658 Pageantry Place \\ Chino Hills, CA 91709 \\ * corresponding author
}

